\title{
DETERMINING SEISMIC SAFETY MARGINS BY NONLINEAR SOIL-STRUCTURE ANALYSIS
}

\author{
SUNAY STÄUBLE AKCAY ${ }^{1}$, ANDRII NYKYFORCHYN ${ }^{1}$, JENS-UWE KLÜGEL ${ }^{1}$,PAYMAN KHALILI \\ TEHRANI ${ }^{2}$, BENJAMIN KOSBAB $^{2} \&$ IMAN TALEBINEJAD ${ }^{2}$ \\ ${ }^{1}$ NPP Goesgen, Switzerland. \\ ${ }^{2}$ SC Solutions Inc, U.S.A.
}

\begin{abstract}
The nuclear power plants (NPP) in Switzerland have to review their plant safety against the updated seismic hazard (Uniform Hazard Spectra, from $10^{-3} / \mathrm{a}$ to $10^{-7} / \mathrm{a}$ - denoted as ENSI-2015) - by performing both deterministic and probabilistic safety analyses. For this purpose, a method for direct estimation of seismic safety margins based on nonlinear soil-structure analysis was developed and applied for systems and components located inside the reactor building of NPP Goesgen. The method is based on the evaluation of safety factors derived from scaling of response spectra for different hazard levels. For this purpose, two sets of deterministic in-structure floor response spectra (ISRS) were developed taking into account soil-structure interaction (SSI). The first set consists of the new linear elastic ISRS for the reference Review Level Earthquake (UHS, frequency of exceedance of $10^{-4} / \mathrm{a}, \mathrm{PGA}=0.41 \mathrm{~g}$ (mean value), called NESK3 in Swiss national regulations). The second one consists of the calculated nonlinear ISRS computed for the Safety Margin Review Level Earthquake (UHS, frequency of exceedance of $10^{-5} / \mathrm{a}, \mathrm{PGA}=0.71 \mathrm{~g}$ (mean value), SMRLE). For obtaining the ISRS an equivalent linear-elastic 3D finite element model of the reactor building and the associated soil column (Soil structure analysis (SSI) in frequency domain, SASSI (ELFD), for NESK3) as well as a nonlinear model (SSI in time-domain using LSDYNA, for the SMRLE (NLTD)) were developed. Soil nonlinearity for the latter was incorporated through a hysteretic plasticity model whose shear response is dependent on soil effective pressure. To calibrate the plasticity model, gravel's shear-stiffness degradation-curve was modified to produce shear strength values consistent with the laboratory-measured friction angle. It is demonstrated that the direct estimation of safety margins by nonlinear soil-structure analysis yields more realistic results than extrapolations common to standard fragility analysis methods.
\end{abstract}

Keywords: Fragility Analysis, Nonlinear Soil-Structure Analysis, Seismic Safety Margins.

\section{INTRODUCTION}

On May 26, 2016, the Swiss Nuclear Safety Inspectorate terminated the long-term probabilistic seismic hazard assessment (PSHA) based on the SSHAC level 4 methodology [1] for the sites of Swiss Nuclear Power Plants (NPPs) by legal ordinance. Based on the results of 18 years of investigations, the Inspectorate defined the seismic hazard for all sites in terms of probabilistic hazard curves reaching from a frequency of exceedance of $10^{-3} / \mathrm{a}$ to $10^{-7} / \mathrm{a}$ combined with the associated uniform hazard spectra (UHS). According to Swiss regulations, all nuclear power plants have to withstand natural events occurring with a frequency of exceedance of $10^{-4} / \mathrm{a}$ within legally defined radiological consequences for the environment and the population outside the plant area. Swiss NPPs have to provide the corresponding safety case based on deterministic safety analysis. For earthquakes, this includes a civil engineering code-based demonstration of safety for all structures, systems and components (SSCs) needed for plant shutdown as well as an assessment of the radiological consequences for plant transients caused by an earthquake. Furthermore, it is requested to demonstrate the availability of additional safety margins to ensure the robustness of plant design and plant operations.

For the demonstration of safety margins, methods related to fragility analysis [2] are accepted for use. 
A key element of fragility analysis consists in the assessment of the factor of safety, relating the seismic capacity of an SSC to its expected response for the review level earthquake [2]. With respect to the determination of safety margins this approach has its limitations, because it is bounded to a specific shape of the UHS. It does not take into account the change of the shape of the UHS with increasing seismic hazard (decreasing frequency of exceedance). Therefore, care must be taken when using safety factors obtained by the usual fragility analysis approach to predict the response of an NPP for earthquakes significantly exceeding the review level earthquake. This provides the cause for developing an alternative approach which is based on the direct comparison of the response of SSCs for different hazard levels taking into account the shift from a nearly linear-elastic response of the coupled soil-structure-component system model to a largely nonlinear response of the system model with increasing hazard. This allows for a direct estimation of seismic safety margins. This refined methodology for the assessment of safety margins is demonstrated on the example of SSCs located inside the reactor building of NPP Goesgen.

\section{METHODOLOGY}

The methodology proposed consists of the following steps:

1. Definition of the reference hazard levels used in the analysis and preparation of hazard data. At least two different hazard levels have to be considered, the lower one has to correspond to the hazard level for which a nearly linear-elastic response of soil (for soil sites) and all relevant SSCs, which are part of the safe shutdown list of the plant, is expected to occur. If a preliminary fragility analysis based on the standard method [2] is available the hazard level can be defined as being slightly higher than the HCLPF (High Confidence of Low Probability of Failure)-value of safety significant equipment required for emergency core cooling (ECC) or for emergency power supply, whatever is lower. If safety margins are to be estimated for purpose of a seismic risk assessment (SPRA) the higher hazard level can be defined based on the frequency of exceedance. The frequency of exceedance should approximately correspond to the expected total core damage frequency of the plant. For a seismic margin assessment, the higher hazard level typically corresponds to the review level earthquake (RLE) matching the objectives of the safety assessment for the plant.

Hazard data required include the relevant response spectra (for a PSHA as in the example, the UHS), site properties (in case of this study site investigations were a part of the seismic hazard analysis (SHA) performed), and a set of time-histories required for the dynamic soil-structure analysis and for the analysis of SSCs. The time-histories have been derived from the deaggregation results of the seismic hazard analysis. For a realistic analysis, the energy content of the time-histories has to correspond to the deaggregation results in terms of magnitude and distance. If possible, natural time-histories shall be used, directly. Because response spectra of natural time histories typically are significantly lower than the UHS from a PSHA [3] natural time-histories may have to be scaled to the UHS. In this case, care shall be taken that the energy content of the selected time histories measured in Arias intensity falls inside the range of empirical observations for the hazard background established by deaggregation of PSHA results. For a deterministic SHA recorded time-histories including the scatter of data can be used directly. 
2. Preparation of standard model for soil-structure interaction of buildings. Typically, equivalent linear-elastic models in frequency domain (ELFD) are used for this purpose. Soil data is used for the lower hazard level for which a nearly linear elastic response of soil and structures is expected. To prepare the nonlinear analysis needed for safety margin assessment, an equivalent linear model in time-domain (ELTD) has to be developed to support the subsequent comparison of results between linear-elastic models and nonlinear models for the different hazard levels.

3. Preparation of a non-linear model in time-domain (NLTD) for the higher hazard level, based on where the response of soil (for soil sites) or of the weaker SSCs is expected to deviate from linear elastic response.

4. Verification of the NLTD model by comparing the results of the NLTD with the results of ELFD for the lower hazard level employing the same site data. The verification shall at least include a comparison of the response of the soil column (for soil sites) and may have to be expanded to a comparison of corresponding in-structure floor response spectra (ISRS).

5. Computation of ISRS for both hazard cases, for the lower one using the ELFD, for the higher one using the NLTD.

The safety factor can now be derived in form of an adjustment factor to the safety factor obtained by the standard method (see eqn. (1)):

$$
C F(f)_{S}=\frac{\operatorname{ISRS}(f)_{L}}{\operatorname{ISRS}(f)_{H}} \frac{P G A_{H}}{P G A_{L}}
$$

The indices $\mathrm{H}$ and $\mathrm{L}$ denote the higher and the lower hazard level, respectively. PGA denotes the ground motion (frequently peak ground acceleration PGA is used), which is used to express the capacity of SSCs. $C F(f)$ is the frequency dependent adjustment factor, which can be multiplied with the safety factor derived from the standard fragility method in order to account for nonlinearities. Using eqn (1) is the simplest approach to obtain a refined safety factor. For obtaining a fragility function, the uncertainties have to be estimated separately for the non-linear model. Alternatively, it is possible to perform a direct estimation of the HCLPF value for a specific SSC if an overall capacity assessment for instance given by the SQUG GIP procedure is available.

\section{APPLICATION FOR THE REACTOR BUILDING OF NPP GOESGEN}

\subsection{Goesgen nuclear power plant}

The Goesgen Nuclear Power Plant, commissioned in November 1979 is located in the Däniken municipality, Switzerland. As shown in Fig. 1, the plant has several buildings including the reactor building (ZA00/ZB00) which is surrounded by the reactor auxiliary building (ZC00) on the west side and the emergency feed building (ZV00) and switchgear building (ZE00) on the south side. The analysis for obtaining safety factors by non-linear analysis focuses on the seismic behavior of the reactor building. The building is about $60 \mathrm{~m}$ tall and is founded on a $62 \mathrm{~m}$ diameter mat foundation, which is $2.7 \mathrm{~m}$ thick. The bottom $9 \mathrm{~m}$ of the reactor building is embedded, though embedment is effective only along approximately half 


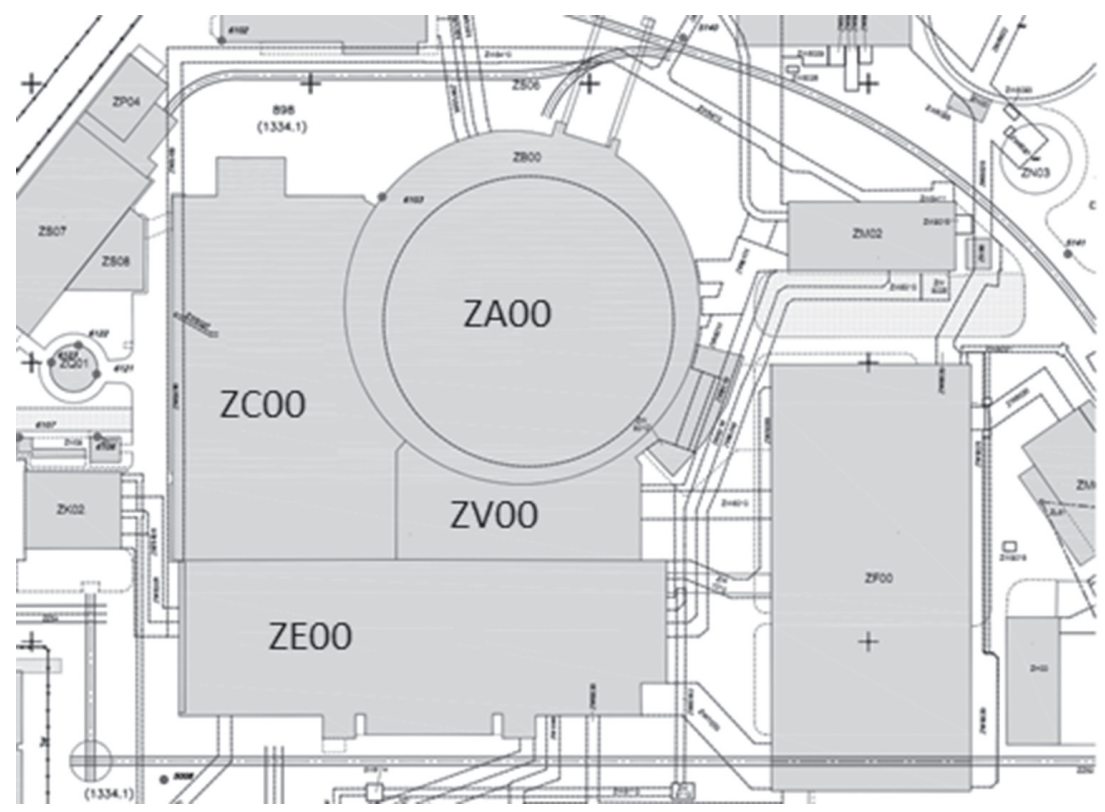

Figure 1: Goesgen nuclear power plant—plan view.

of the building perimeter since there is no effective embedment along the boundary with the neighbour buildings.

\subsection{Definition of seismic hazard}

The UHS for the frequency of exceedance of $10^{-4} / \mathrm{a}$ and the UHS for the frequency of exceedance of $10^{-5} / \mathrm{a}$ were derived from the ENSI-2015 SHA [5] and used as the lower and the higher seismic hazard correspondingly. Seismic capacity of SSCs is expressed in terms of PGA.

\subsection{Site characteristics}

The ground under the Goesgen plant consists of a 20 to 30-m thick layer of gravel laid on a solid limestone formation, which provides a stable base for the plant. The initial and degraded shear wave velocities for 1E-4 UHS and 1E-5 UHS hazard levels as well as compression wave velocity versus depth are shown in Fig. 2.

The ground water table is at a depth of $6.5 \mathrm{~m}$ below surface. Soil properties were developed based on detailed site investigations that were part of both the PEGASOS [6], as well as the PEGASOS Refinement Project (PRP). The later provided the basis for ENSI-2015 with respect to site characteristics.

\subsection{Input ground motion}

The assessment of safety factors is based on the computation of probabilistic ISRS for the reactor building floors. Two different sets of 30 time-histories at rock level were developed 

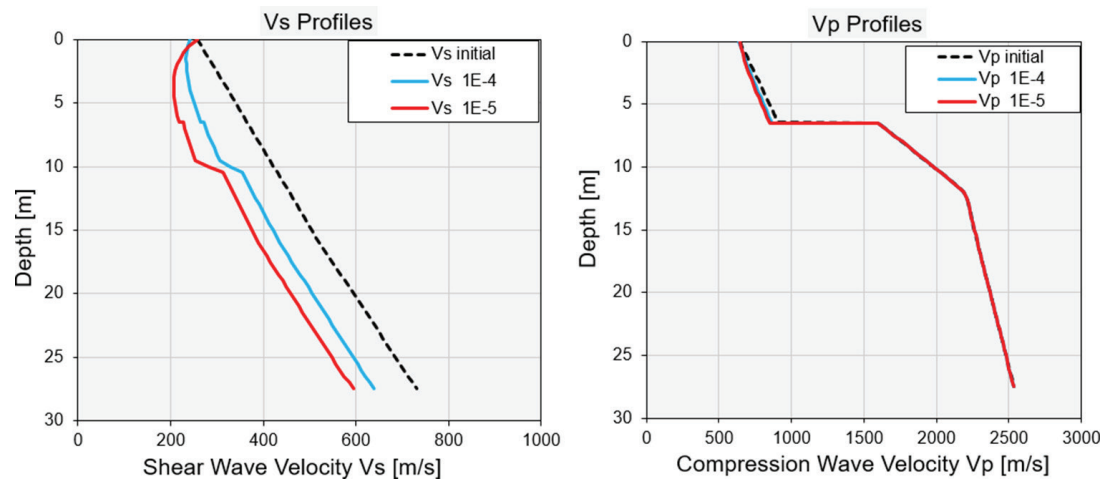

Figure 2: Initial and strain compatible shear wave velocity and compression wave velocity soil profiles of NPP Gösgen.

for representing the deaggregation results of the ENSI-2015 SHA by adequate input ground motions. These sets include some variability with respect to the energy content of the time-histories reflecting the scatter of empirical data for the relevant magnitude-distance bins of the deaggregation results.

Figure 3 shows the deaggregation results for the frequency of exceedance $10^{-4}$ /a for PGA $(100 \mathrm{~Hz})$. In accordance with these results, recorded time-histories were selected from the RESORCE database [8] in the following interval of parameters:

\begin{tabular}{cccc}
\hline Hazard Level & Magnitude $\left(\mathbf{M}_{\mathbf{w}}\right)$ & Distance $\left(\mathbf{R}_{\mathbf{j b}}\right), \mathbf{k m}$ & PGA, [g] \\
\hline $10^{-4} / \mathrm{a}$ & $4.5-7.5$ & $3-40$ & $0.2-0.6$ \\
$10^{-5} / \mathrm{a}$ & $4.5-7.5$ & $3-30$ & $0.4-1$ \\
\hline
\end{tabular}
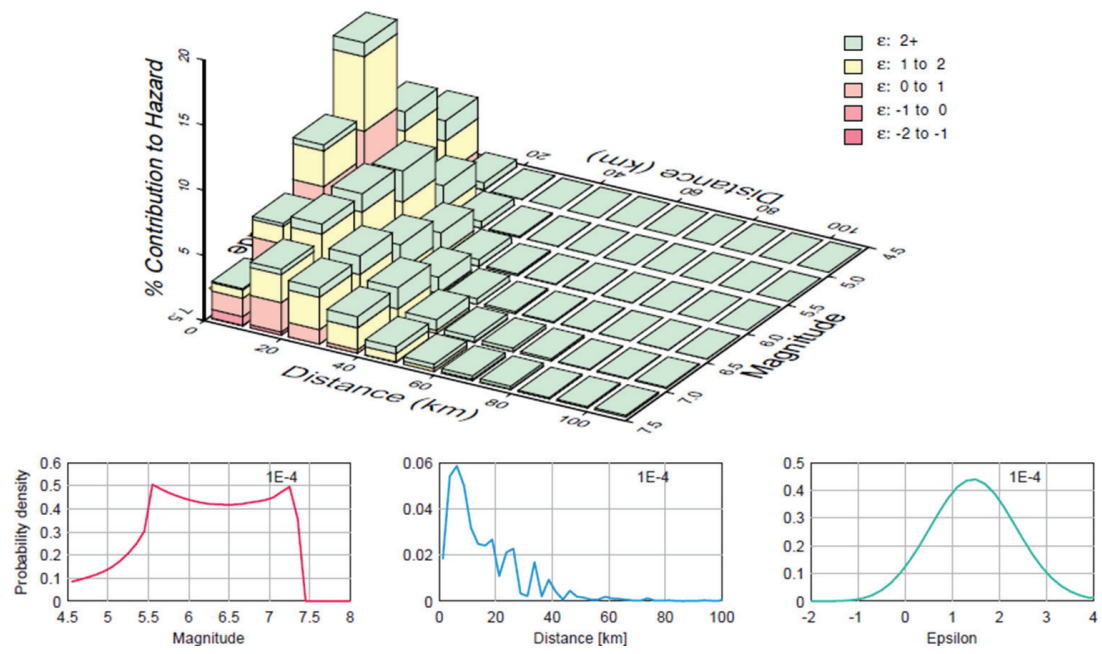

Figure 3: ENSI-2015-Deaggregation results for annual hazard level 10-4, PGA (figure taken from [7]). 

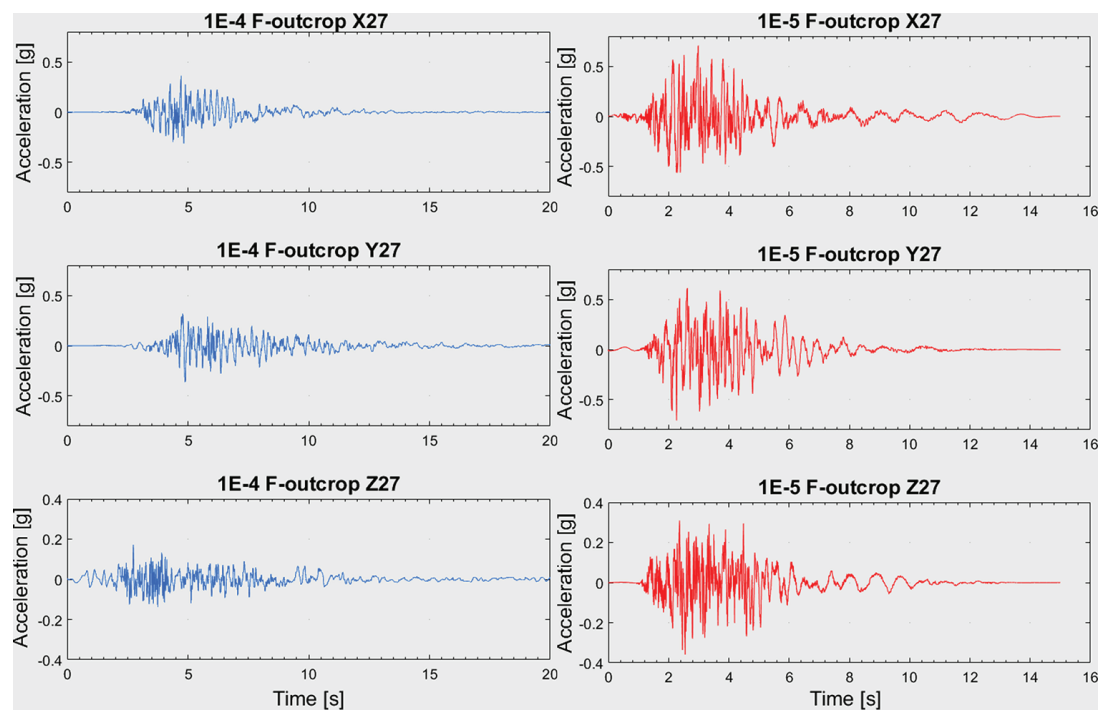

Figure 4: One of UHS 1E-4 (left) one of UHS 1E-5 (right) time-histories examples at foundation level.

The time-histories were developed as spectrally matched to the corresponding UHS of ENSI-2015 [7] at foundation elevation (2 example shown in Fig. 4), then linearly deconvolved based on best estimate strain-compatible soil properties to the top of the bedrock as outcrop motion by Shake. Spectral matching used the approach described in [9]. Energy correction was performed if necessary by taking credit of the observed negative correlation between strong-motion duration and ground motion amplitude as demonstrated in [10]. The correction is applied only if the seismic energy of the scaled time-history measured in terms of Arias Intensity $\mathrm{I}_{\mathrm{A}, \mathrm{s}}$ significantly deviated from the empirically observed values. The Arias Intensity of the scaled time-history should remain within the boundaries of the interval of $\pm 1.5 \sigma$ centered at the empirically observed value of the Arias Intensity $\mathrm{I}_{\mathrm{A}, 0}$.

\subsection{Description and verification of models}

Before studying the nonlinear effects, the equivalent linear SSI model of the reactor building and the site was developed and analyzed in both time domain (ELTD) and frequency domain (ELFD) at $10^{-4}$ UHS hazard level. The ELTD results were compared to those of the commonly employed ELFD analyses to establish a base alignment between the two approaches. The verified ELTD "base" model was then modified to study the nonlinear effects.

The ELFD model used in the analysis is a standard SASSI [4] model frequently employed in the soil-structure analysis of NPPs. This model was developed outside the scope of this study as part of the standard fragility analysis for SSCs of the plant following the general methodology of [2] and adapted to the additional requirements in [11].

The finite element model used for ELTD analyses is shown in Fig. 5. The mat foundation, exterior concrete dome and interior steel sphere are represented with shell elements. The floor beams and columns are modeled with beam elements. A viscoelastic constitutive model is used for all beam and shell elements. Damping ratios of $4 \%$ and $2 \%$ are assumed for the reinforced concrete and steel, respectively. 


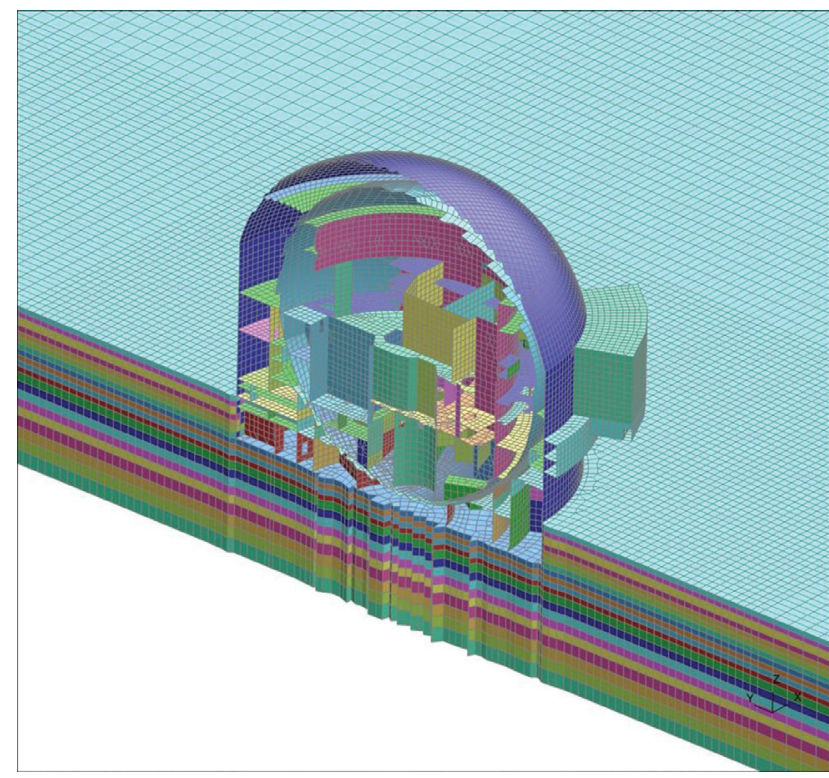

Figure 5: FE model of the reactor building and soil layers.

The underlying soil medium shown in Fig. 6 was modeled using solid finite elements. The model bottom boundary is $-27.55 \mathrm{~m}$ below the ground surface. The soil domain's side boundaries are $470 \mathrm{~m}$ from the center of the structure in each direction. There are 20 soil layers in the FE model with passing frequency in excess of $40 \mathrm{~Hz}$ at $10^{-4}$ UHS hazard level.

Contrary to the common practice of employing simplified and frequency-dependent damping formulations, e.g. Rayleigh, in time domain, a viscoelastic hysteretic material model was used to simulate the soil response to seismic excitations. This material model is capable of modeling the nearly-frequency-independent viscoelastic behavior of soil subjected to cyclic loading.

The in-situ total soil stresses were initialized in the beginning of the analysis. This allows for properly simulating the soil equilibrium under the gravity load. The material properties for the underlying elastic half space modeled as a nonreflecting boundary via Lysmer's approach were derived based on the $\mathrm{V}_{\mathrm{s}}(2500 \mathrm{~m} / \mathrm{s})$ and $\mathrm{V}_{\mathrm{p}}(4330 \mathrm{~m} / \mathrm{s})$ at a depth of $27.55 \mathrm{~m}$ below the surface.

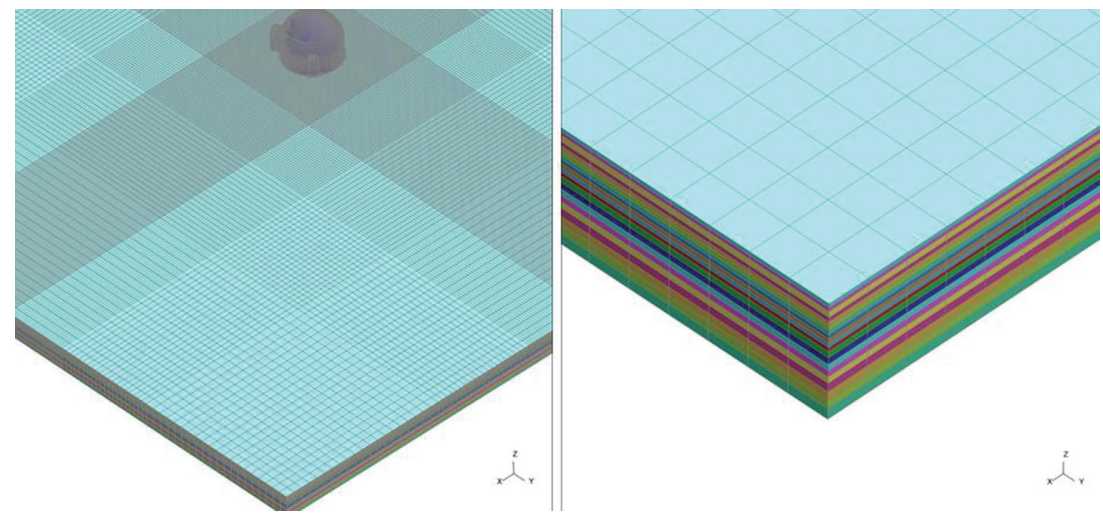

Figure 6: Isometric view of soil FE model. 
Consistent with structural drawings, and to account for the expansion joints between reactor building and neighbor buildings, structural nodes are detached from the soil nodes at the interface with the neighbor buildings. This configuration is referred to as partial embedment. Another embedment configuration, referred to as full embedment, was also considered in which all structural nodes on the perimeter of the structure are fully connected to the soil nodes as a part of sensitivity study. For both configurations, the bottom of the mat foundation is fully connected to the underlying soil layer.

SSI results in the form of ISRS obtained via ELTD and ELFD approaches are compared to verify the general alignment between the two approaches. ELFD analyses, which represent the state of practice within the nuclear industry, were performed in SC-SASSI [4]. The ELTD analyses were performed by simultaneously applying the three components of ground motions $\left(10^{-4} / \mathrm{a}\right.$ UHS $)$ at the base of the soil domain as rock outcrop using LS-DYNA.

Comparison of ISRS extracted at multiple component locations within the reactor building shows a good agreement in the resonance frequency predictions as well as amplitude with some response differences between the ELTD and ELFD results as presented in [12].

In NLTD analyses, a nested multi-surface hysteretic plasticity model with effective pressure-dependent stiffness and strength was used to simulate the nonlinear soil response. The main inputs are a constant value for the bulk modulus and a shear stress versus shear strain curve, i.e. yield surface, at a reference pressure (usually the at-rest in-situ effective pressure). The reference pressure is used to model the pressure dependency of gravel's shear strength as its confinement changes due to the building weight and shaking. The effect of structure's weight on gravel's shear response is more significant for surface/shallow founded structures because the weight of the structure can be significantly larger than the excavated soil weight. In the case of the reactor building, the structure's weight is about 3 times the weight of the soil it has replaced.

There are significant discrepancies between the soil shear strength implied based on $G / G_{\max }$ curves and shear wave velocity, versus the soil shear strength determined based on the strength parameters measured in the laboratory, i.e. friction angle and cohesion. Thus, the $\mathrm{G} / G_{\max }$ were modified to limit the stress at high shear strains to cap it at correct shear strength of the soil. Figure 7 shows a representative example for this correction.

\section{Layer 8}

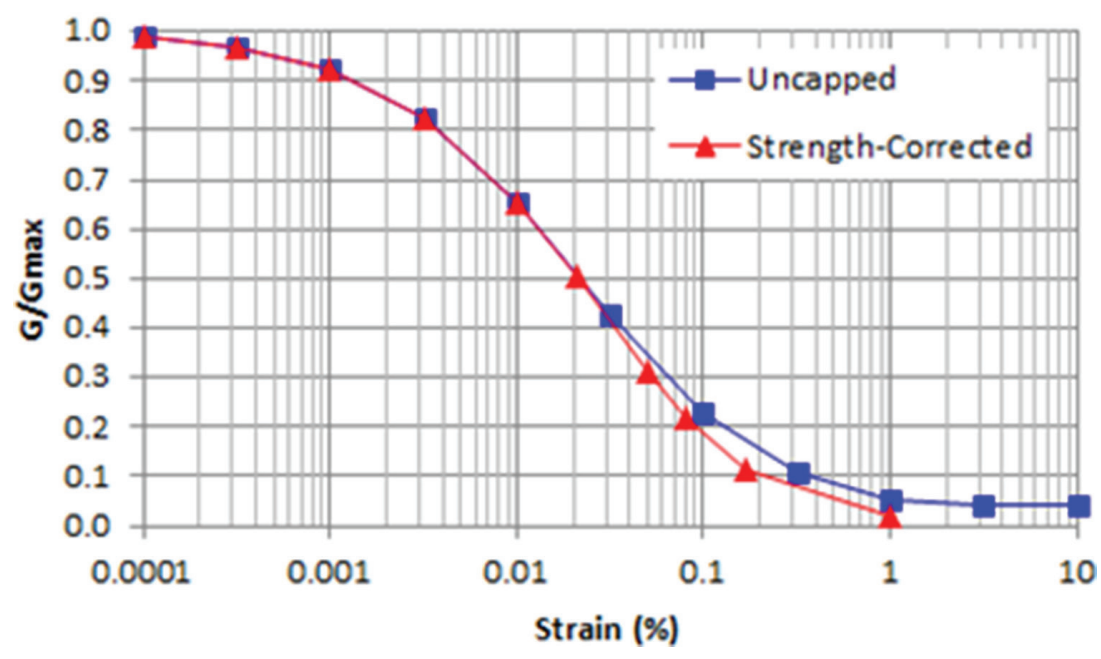

Figure 7: Representative $G / G_{\max }$ curve. 


\section{COMPUTATION OF ISRS AND ASSESSMENT OF SAFETY FACTORS}

The ELFD (for the $10^{-4} / \mathrm{a}$ UHS median PGA $=0.37 \mathrm{~g}$ ) and NLTD (for the $10^{-5} / \mathrm{a}$ UHS median PGA=0.62g) models were used to compute the frequency dependent adjustment factor according to eqn (1) to the safety factor obtained by the standard fragility method [2].

$$
C F(f)_{S}=\frac{\operatorname{ISRS}(f)_{L}}{\operatorname{ISRS}(f)_{H}} \frac{0.62}{0.37}
$$

The following Figs. 8-11 show the comparison of the ISRS spectra for the two different hazard levels as well as the computed adjustment factors for two different elevations in the reactor building. The comparison of spectra shows that the ISRS for the higher hazard shows a spectral shift of peaks towards lower frequencies as well as some damping effect caused by the nonlinear soil model. The frequency dependent adjustment factors are compared to the standard fragility method [2] that would result in an adjustment factor equal to one. It is obvious that the adjusted safety factors obtained by the proposed modelling approach may differ significantly from the results of the standard method, which is based on pure extrapolations.

These differences can have significant effects on the results of safety and risk assessment. For example, it can be seen, that in the frequency range around $2 \mathrm{~Hz}$ the standard method leads to an overestimation of the safety factor. This frequency range is very important for the safety assessment of reactor vessel internals and fuel elements. For higher frequencies, the adjustment factor oscillates around the factor 1 . Therefore, in this example the standard method may provide a reasonable approximation of the safety factor for SSCs with first natural frequencies starting from around $8 \mathrm{~Hz}$ without the need for using the more complex proposed approach. This is the typical range of natural frequencies for many components in a nuclear power plant (starting from pumps, valves and electrical cabinets) if they are fixed rigidly to the floor. For very low frequencies, significantly higher safety factors are observed. This range of low frequencies is not very typical for SSCs in a nuclear power plant. The nonlinear response of SSCs is mainly driven by material and geometrical parameters which are well known and which are attributed mainly by aleatory variability.

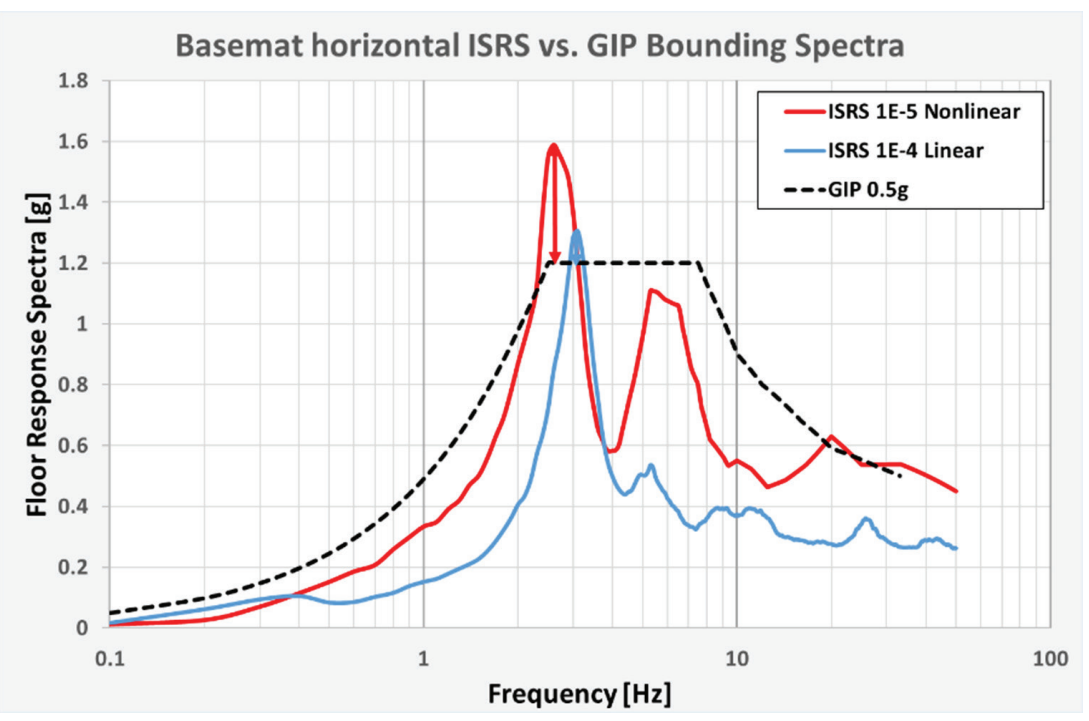

Figure 8: Comparison of ISRS basemat. 


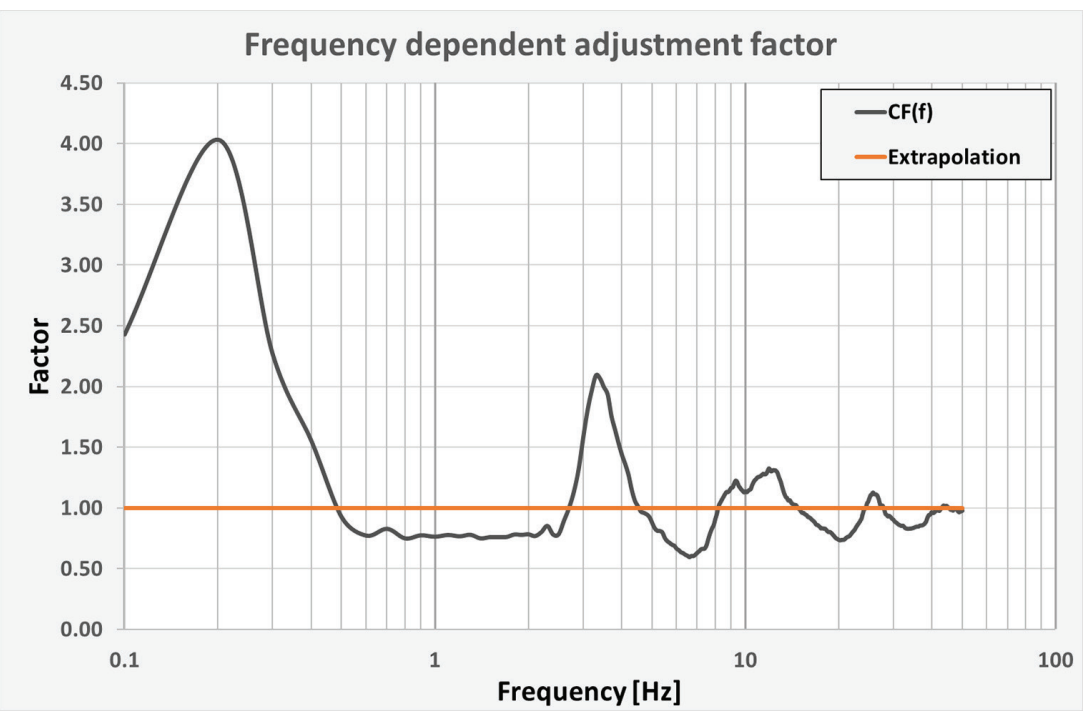

Figure 9: Frequency-dependent adjustment factor $C F(f)$ for basemat.

A significant contributor to the adjustment factor is due to the expected 'frequency shift' between the two hazard levels. Typically, SSC fragility has to look at SA across a range of frequency to account for uncertainty in frequency estimate of the SSC (equipment) itself.

As an example, a comparison of the ISRS of a safety injection pump in basemat elevation with capacity characterized by the generic bounding spectrum at $0.5 \mathrm{~g}$ PGA from the Seismic Qualification Utility Group Generic Implementation Procedure (SQUG GIP) [13] (Fig. 8), which can be applied for this type of equipment. The calculation of the seismic fragility is based on the EPRI approach [14], median capacity is:

$$
A_{m}=F_{c} F_{R S} P G A
$$

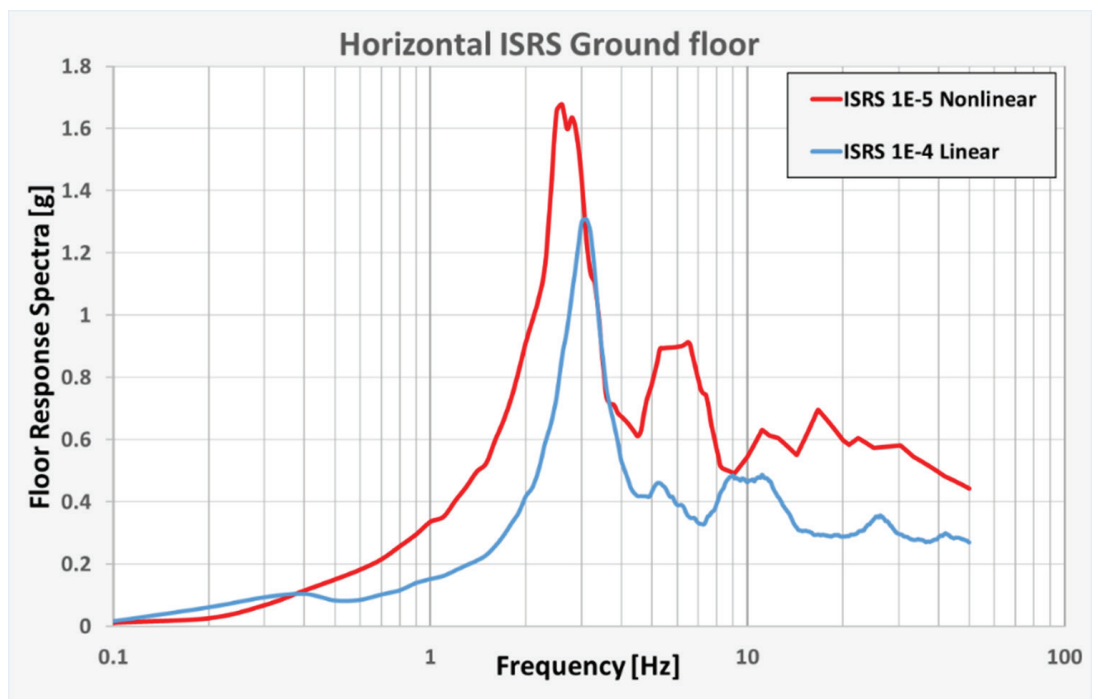

Figure 10: Comparison of ISRS at the ground floor. 


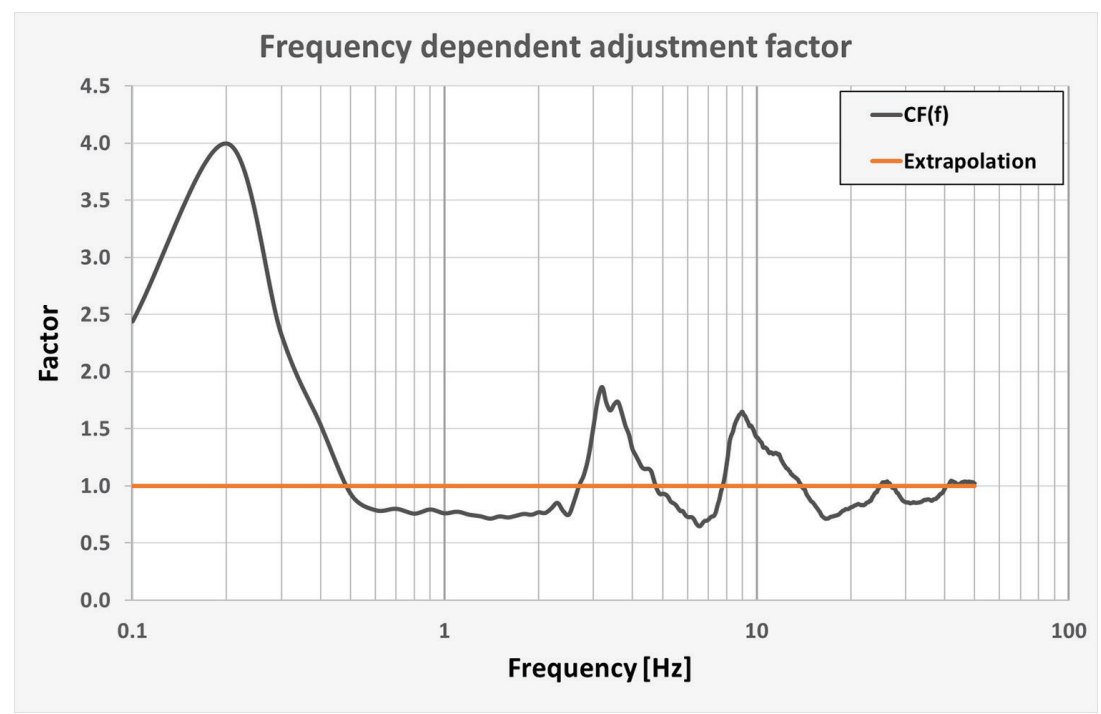

Figure 11: Frequency-dependent adjustment factor $\mathrm{CF}(\mathrm{f})$ for the ground floor.

$\mathrm{F}_{\mathrm{RS}}$ is the structure response safety factor

$\mathrm{F}_{\mathrm{c}}$ is the component capacity factor

$$
F c=\frac{C_{I}}{C_{C}} \frac{T R S}{R R S}
$$

$\mathrm{C}_{\mathrm{I}}$ is the capacity increase factor

$\mathrm{C}_{\mathrm{c}}$ is the peak-clipping factor of ISRS.

The test response spectrum TRS is the GIP bounding spectrum at $0.5 \mathrm{~g}$ PGA multiplied by the factor of 4.0 according to [14].

The required response spectrum RRS is the ISRS at the component location in the structure.

While the other parameter being constant, the seismic capacity of the component is largely determined by the minimum ratio of $\left(\frac{\mathrm{GIP}(\mathrm{f})}{\operatorname{ISRS}(\mathrm{f})}\right)$ and PGA values:

For lower hazard level (1E-4, PGA=0.37g, linear): $\min \left(\frac{\mathrm{GIP}(\mathrm{f})}{\operatorname{ISRS}(\mathrm{f}) L}\right)=0.92(\mathrm{f}=3.1 \mathrm{~Hz})$

For higher hazard level (1E-5, PGA=0.62g, nonlinear): $\min \left(\frac{\mathrm{GIP}(\mathrm{f})}{\operatorname{ISRS}(\mathrm{f}) H}\right)=0.76(\mathrm{f}=2.6 \mathrm{~Hz})$

After normalizing from higher hazard level to the lower hazard level by PGA, we obtain for 1E-4 higher margin:

$$
\min \cdot\left(\frac{\operatorname{GIP}(\mathrm{f})}{\operatorname{ISRS}(\mathrm{f})}\right)=0.76 * \frac{0.62}{0.37}=1.27>0.92
$$

Median capacity ratio of higher hazard level (nonlinear) to lower hazard level (linear), according to GIP: 


$$
\frac{A_{m}(1 E-5)}{A_{m}(1 E-4)}=\frac{\mathrm{F}_{\mathrm{C}} * \mathrm{FRS} * \mathrm{PGA}}{\mathrm{F}_{\mathrm{C}} * \mathrm{FRS} * \mathrm{PGA}}=\frac{\frac{C_{1}}{C_{C}} * 4 * 0.76 * \mathrm{FRS} * 0.62}{\frac{C_{1}}{C_{C}} * 4 * 0.92 * \mathrm{FRS} * 0.37}=1.38
$$

\section{CONCLUSIONS}

A methodology was developed allowing determining safety margins of SSCs of a nuclear power plant directly using nonlinear structural analysis. The comparison with standard extrapolation methods established in [2] and commonly used for fragility analysis being part of safety margin assessments or seismic probabilistic risk assessment (SPRA) has shown that significant differences may occur. The standard methods are not necessarily conservative/unconservative and may lead to over/under-estimation of safety margins for reactor vessel internals and fuel elements as an example class. In the higher frequency range, the standard methods appear to be sufficiently robust. Due to the large progress in computer technology, it is recommended to improve the commonly used standard methods by more realistic nonlinear analysis methods allowing for a higher quality of safety and risk assessment of nuclear power plants.

\section{REFERENCES}

[1] Senior Seismic Hazard Analysis Committee, Recommendations for Probabilistic Seismic Hazard Analysis, NUREG/CR-6372, 1997.

[2] EPRI, Seismic Fragility Application Guide, TR 1002988, 2002.

[3] Klügel, J.U. \& Stäuble Akcay, S., Development of intensity compatible time-histories for dynamic analysis of buildings. In 16th World Conference on Earthquake, 16WCEE 2017, Santiago Chile, 2017.

[4] SC Solutions, SC SASSI Manual, Version 2.1.14, 2016.

[5] ENSI, Verfügung: Erdbebengefährdungsannahmen ENSI-2015 für die Standorte der Schweizer Kernkraftwerke, Brugg: ENSI, 26.5.2016.

[6] NAGRA, Probabilistische Erdbebengefährdungsanalyse für die Standorte der Schweizer Kernkraftwerke (PEGASOS), Nagra, Wettingen, 2004.

[7] PROSEIS, Calculation of the Seismic Hazard at the Four NPP Sites Based on the Hybrid SED-PRP Model, Technical Report, 2015.

[8] European-Mediterranean Seismological Center (EMSC), Resource Reference Database for Seismic Ground-Motion in Europe, 2013.

[9] Atalik, L.A. \& Abrahamson, N., An improved method for non-stationary spectral matching. Earthquake Spectra, 26(33),pp.3034-3047,2010.https://doi.org/10.1193/1.3459159

[10] Vanmarcke, E.H. \& Lai, S.P., Strong-motion duration and RMS amplitude of earthquake records. Bulletin of the Seismological Society of America, 70(4), pp. 1293-1307, 1980.

[11] ENSI, Methodik deterministischer Erdbebennachweise der Schweizer Kernkraftwerke, ENSI-AN-8567, Brugg, 2013.

[12] Khalili Tehrani, P., Talebinejad, I., Kosbab, B., Nykyforchyn, A., Stäuble, S. \& Klügel, J., Effects of nonlinearities on seismic soil-structure-interaction behavior of a nuclear plant reactor building: A case study. Technical Innovations in Nuclear Civil Engineering (TINCE), Paris, 2018.

[13] SQUG, Seismic Qualification Utility Group, Generic Implementation Procedure (GIP) for Seismic Verification of Nuclear Power Plant Equipment, Revision 3A, 2001.

[14] EPRI, Seismic Fragility Application Guide Update, Report 1019200, December 2009. 